\title{
Employability Promoting Ways of Middle Vocational Undergraduate Students based on Career Planning
}

\author{
Bing Yang ${ }^{1, a}$, Anqi Gao ${ }^{2, b}$ \\ ${ }^{1}$ College of Finance and Trade, Bohai University, Jinzhou, 121013, China \\ ${ }^{2}$ Jinzhou Power Supply Company, State Grid Liaoning Electric Power Supply Co., LTD., Jinzhou, 121100, \\ China \\ ayangbing2884567@163.com, bangel12333233@126.com
}

Keywords: career planning; middle vocational undergraduate; employability; promoting ways

\begin{abstract}
Old educational concept and incomplete education system, lack of awareness of the role of career planning and idea, restricting the development of career planning, leading middle vocational career planning education difficult to effectively implement. Based on the classical theory of career planning, this paper analyzes the role of career planning to enhance the employability, and puts forward the way of career planning to enhance the employability of middle vocational undergraduate students. The specific ways include: construct career planning education system, promote the rationalization of employment awareness; establish career planning teacher team, ensure the smooth implementation of student employment; whole-way guide career planning education, promote students' comprehensive ability; carry out personalized career guidance, define student striving direction.
\end{abstract}

\section{Introduction}

Career planning, refers to the basic combination of personal development and organizational development. Personage analyzes, summarizes and determines the career goals through the career planning of subjective and objective factors, achieves this goal, arranges the process of career development in advance. Everyone is the planner and implementer of his career, career planning requirements according to their own "career interests, characteristics of personality, aptitude, professional knowledge and skills" and other factors, giving consideration to a variety of external factors, through comprehensive trade-off, choosing the best place which can play good qualities, maximize self-worth. In essence, career planning is the process of pursuing the best career.

Due to the lack of scientific career planning concept, school's career guidance and service is seriously inadequate, students did not form clear employment career direction and career development goal, personal career development is confused, and it is difficult to participate in targeted skill training, resulting in the employment problem of students graduation when the individual ability and business needs do not match.

Career planning is increasingly valued by students, schools and society, and is an important way to improve employability. In the context of the multi-faceted and diversified pattern of employment guidance, we should pay more attention to career planning education, and strive to make the employment guidance more targeted at the same time, more "scientific" and "effective." In view of the characteristics of middle vocational undergraduate students, this paper puts forward the ways to improve the employability from the perspective of career planning, fundamentally solve the employment problems of middle vocational undergraduates and provide guidance for students' lifelong development. 


\section{Classical Theory of Career Planning}

Career planning theory is developed by the concept and theory of career guidance. The process of career planning theory not only gradually become mature, but also in practice and continue to apply and test. Some experts and scholars have carried on the thorough research to the career planning and the development theory, have put forward some kinds of classical theory which has the widespread influence, has the guidance and the reference function to the employment instruction and the university students career planning.

(1) Donald E. Super's career development stage theory. Donald E. Super is a representative professional management scientist in the United States. Saber's career development stage theory is a vertical career guidance theory, focusing on the individual's career orientation and career selection process itself to study, human career is divided into five main stages, as shown in Fig. 1.

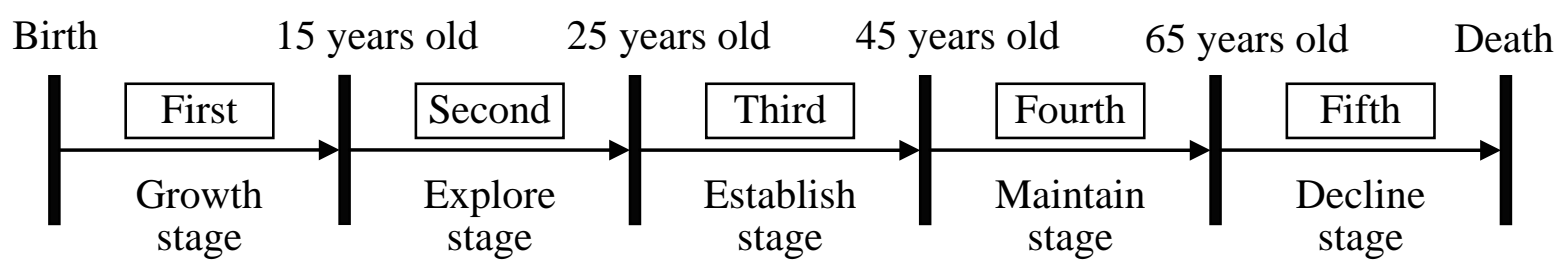

Fig. 1. Career development stage of Donald E. Super

First, Growth stage, the main task is to identify and establish self-concept, the inquisitive career dominated, and gradually consciously cultivate professional ability.

Second, Explore stage, the main task is through the school study self-examination, role identification and career exploration, complete career selection and initial employment.

Third, Establish stage, the main task is to obtain a suitable field of work and seek development. This stage is the center of most people's career cycles.

Fourth, Maintain stage, the main task in this long time is to develop new skills, maintain achievements and social status, maintain the harmonious relationship between the family and work, and look for successors.

Fifth, Decline stage, the main task is to gradually withdraw from the occupation and the end of the career, the development of social roles, reduce the rights and responsibilities to adapt to retirement after life.

(2) John Holland's professional interest theory. John Holland is a professor of psychology at Johns Hopkins University in the United States. He believes that people's personality type, interest and career are closely related, interest is the great driving force of people's activities, all occupation with professional interests can improve people's enthusiasm to promote people actively and happily engaged in work, there is a high correlation between career interests and personality. Holland believes that personality can be divided into "Realistic type, Investigate type, Art type, Social type, Enterprise type, Conventional type" and other six types. The six types are placed in every angle of positive hexagonal triangle, as shown in Fig. 2.

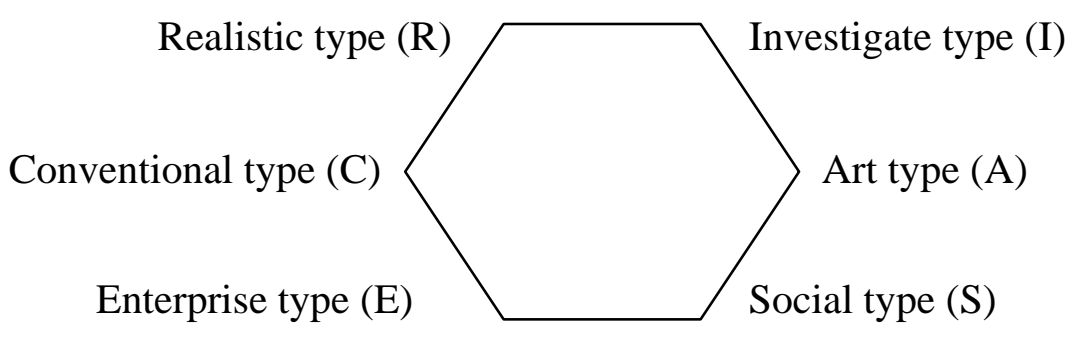

Fig. 2. The relationship between six types

Realistic type (R), willing to use tools to engage in operational work, practical ability, work flexibly, coordinated action. Preference for specific tasks, poor words, conservative, more modest. lack of social skills, like to work independently. 
Investigate type (I), abstract thinking ability, thirst for knowledge, willing to brain, good thinking, do not want to hands. Like independent and creative work. Knowledgeable, knowledgeable, not good at leading others. Consider the problem of rationality, doing things like precision, like logical analysis and reasoning, and constantly explore the unknown areas.

Art type (A), creative, willing to create novel and distinctive results, eager to express their own personality, to achieve their own value. Work ideal, the pursuit of perfection, not heavy reality. With artistic talent and personality. Good expression, nostalgia, mentality is more complex.

Social type (S), like to interact with people, keep making new friends, good talk, willing to teach others. Concerned about social issues, eager to play a social role. Seeking a wide range of interpersonal relationships, more emphasis on social obligations and social morality.

Enterprise type (E), the pursuit of power, authority and material wealth, with leadership. Like competition, dare to take risks, have ambition, ambition. Pragmatic, get used to benefit gains and losses, things have a strong purpose.

Conventional type (C), respect for authority and rules and regulations, like to work according to plan, careful, organized, used to accept the leadership of others, do not seek leadership positions. Concerned about the actual and details of the situation, more cautious and conservative, lack of creativity, do not like adventure and competition, full of self-sacrifice.

(3) Edgar.H.Schein' Career Anchor Theory. The professional anchor is made by Professor Edgar.H.Schein', a well-known professional instructor in the United States. In his view, career development is actually a continuous process of exploration, in this process, everyone according to their own talent, ability, motivation, needs, attitudes and values, etc., gradually formed a more clear and career-related Self-concept. With the person more and more understanding of his own, it will become more and more obvious to form a dominant position of the professional anchor. After a large number of scholars extensive research, the occupational anchor identified as eight types, as shown in Fig.3.

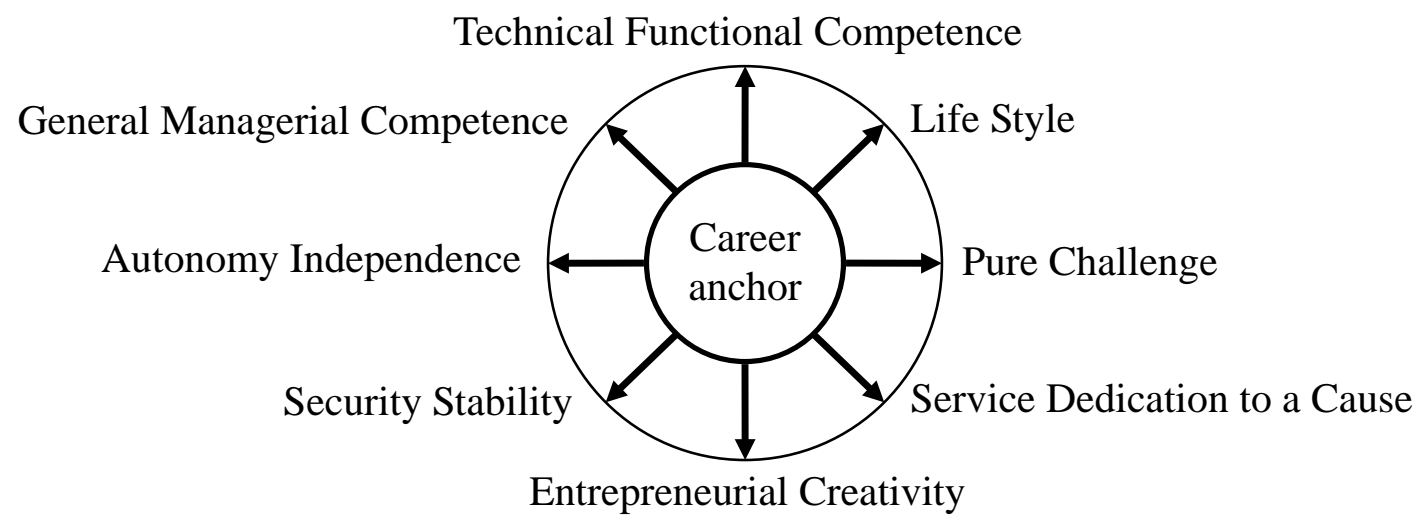

Fig. 3. The relationship between six types

Technical Functional Competence: the pursuit of growth in the field of technology and skills continue to improve, as well as the application of technology and functions of the opportunity. Like to face the challenges from the field of expertise, do not like to engage in general management.

General Managerial Competence: dedicated to job promotion, focused on comprehensive management, alone is responsible for a part of the integration of other people's efforts can be cross-sectoral results, and the success of the company as their work.

Autonomy Independence: hope to arrange your own way of working, working habits and lifestyle. The pursuit of individual ability to work environment, maximize the constraints and constraints of the organization.

Security Stability: the pursuit of work in a sense of security and stability. Concerned about financial security. Sense of stability, including integrity, loyalty, and the completion of the leadership of the work, do not care about the specific positions and work content.

Entrepreneurial Creativity: like to take risks and overcome difficulties. They may be working in someone else company, once the opportunity is coming, they will go out to establish their own company. 
Service Dedication to a Cause: the pursuit of their own recognized core values, help others, improve people's safety. Pursuing this opportunity, even if the transformation of the company will not accept the value of the work which is not allowed to achieve.

Pure Challenge: likes to solve seemingly unsolved problems, overcome tough opponents, overcome the difficulties which can not be overcome. Novelty, change and difficulty are their ultimate goals.

Life Style: combination of personal needs, family needs and career needs. Hoping to integrate all aspects of life into a whole. Need to provide enough flexibility to enable them to achieve this goal of the professional environment.

\section{Role of Career Planning to Improve Employability}

Practice shows that students who participated in career planning, learning more active, sense of target and control ability have been enhanced, choose a career more calm and rational. Therefore, the career planning applied to student employment guidance, for the overall promotion of students' employability to promote students rational employment.

(1) Explore the individual potential of students, enhance the professional competitiveness. Through career planning, students will be able to correctly understand their own personality traits, existing and potential resource advantages, help students re-positioning their own value. At the same time, promote students to their own comprehensive advantages and disadvantages of comparative analysis to assess the gap between personal goals and reality, choose the actual combination of career positioning, find new career opportunities, learn to use scientific methods, and continuously enhance the professional competitiveness.

(2) Achieve the unity of planning and development, provide a clear direction for employment. Career planning is to seek a reasonable direction and development goals of individuals, as well as to achieve the objectives of the overall arrangements and arrangements for the design, with a clear plan and purpose, strengthen the students' understanding and understanding of their own. Find interested areas of occupation, determine their own work, clear into the starting point of society. The most important thing is to clear the goal of life, and make their own life clearer positioning.

(3) Enhance the level of self-awareness, shaping the fresh and rich self. When students plan career orientation, "professional" is no longer the first element to be considered, the need for personal interests, hobbies, abilities and characteristics of a comprehensive analysis, combined with the characteristics of the times to determine the best career goals. Career planning is no longer find a suitable job to achieve personal career goals, more importantly, really understand themselves, planning for the future, the development of life direction.

\section{Ways of Improve Employment Ability for Middle Vocational Undergraduate Students based on Career Planning}

Whether students can successfully employment, depending on the students have the expertise to meet the needs of employers. School is the main part to enhance the employment of secondary vocational college students, learn cultural knowledge in school system, scientifically accept career planning and guidance, and throughout the various stages of school education to help students establish career planning awareness, make career planning, improve the overall quality, and then improve the employability of students. Specific ways of improvement are as follows:

(1) Build career planning education system, promote students employment awareness rationally. The traditional concept of employment is that students see employment as a return to family, school and society, do not take into account the future career development, through career planning and development of employment guidance courses to promote students to employment and career development closely linked, know your own, career and social relations initially. The construction of vocational college career planning education system, should be from the organizational system, operating system and evaluation system to establish and improve three aspects. First, we must improve the management system and service system of the career planning education. Secondly, we 
must establish and perfect the education system and service system of the career planning. Finally, we should establish the evaluation and feedback mechanism to ensure the operation of the life education system and implementation, in order to make vocational students career planning education system healthy and healthy development.

(2) Establish career planning teacher team, ensure the smooth implementation of student employment. At present, there is a general lack of professional career planning guidance teachers in colleges and universities. Many teachers are limited to employment guidance for students, lack of deep understanding of students and society, and can not carry out targeted individualized guidance. They should establish a special vocational school career planning guidance work committee, the career planning guidance teachers into the school teacher training program to strengthen the psychological knowledge learning, as well as the employment situation and economic development and other content-based training, broaden the theoretical perspective , rich professional knowledge, accumulated teaching experience. The establishment of a full-time teachers as the backbone, full-time and part-time combination, relatively stable, high-quality secondary vocational students career planning guidance teachers.

(3) Whole-way guide into career planning education, enhance the comprehensive ability of students. Through the school system of scientific career planning and guidance, throughout the middle vocational education at all stages, help students establish career planning awareness and the development of initial career planning, improve the overall quality of students, and then improve the student's employment skills, need to collect the power of school. Career planning education should start from the new students education, as early as possible that students establish career planning philosophy. Career planning concept should be implanted into the personnel training system, reflecting the common career planning career development. Career planning guidance should be refined to each individual student, reflecting the career planning personality training. The establishment of the school outside the career planning and employment guidance platform for students career planning program to provide opportunities.

(4) Carry out personalized career guidance, clear the direction of student efforts. Career planning should adhere to the principle of personalization. According to the characteristics of different groups of students, given the appropriate guidance. First, guide students to understand the employment situation, determine employment goals, reduce the blindness of career choice, improve the success rate of employment. Second, guide students to understand themselves, understand their own character and expertise, as well as the professional knowledge structure, in accordance with the principle of "choose their own interest, choose their own strengths, choose social needs, choose to promote their own growth", through self- psychological tests, etc., carry out scientific career orientation, training students' need to learn, to improve the need for training and reasonable employment. Third, understand the professional quality of employment required. According to the different needs of the staff, combined with the actual situation of students, combined with different vocational skills, employment guidance and information consultation and other related training to help students establish suitable career planning program.

\section{References}

[1] L. H. Chen, "Application of career planning in higher vocational students' career guidance," Journal of Fujian Radio \& TV University, vol. 13, no. 5, pp. 39-41, 2005.

[2] C. X. Zhu, L. B. Zhao, "Current situation and countermeasures of college students' career planning," Journal of Liaoning University of Technology (Social Science Edition), vol. 18, no. 3, pp. 82-85, 2016.

[3] J. L. Kong, "A Study on College Students' Employment Difficulty in Prospective of Career Planning," Journal of Shangluo University, vol. 31, no. 1, pp. 74-77, 2017.

[4] G. B. Ma, "Career planning and college students' ability training," Journal of Jiamusi Vocational Institute, vol. 34, no. 1, pp. 300+302, 2017. 
[5] X. L. Li. Yang, "The influence of career planning of college students on the employment of college students," Contemporary Education Research and Teaching Practice, vol. 4, no. 6, pp. 104, 2016.

[6] Q. Dong, "Career planning and effective employment of college students," Journal of Shandong Agriculture and Engineering University, vol. 33, no. 2, pp. 33-34, 2017. 